\title{
Perspectivas Normativas para o Legado Digital Pós-Morte Face à Lei Geral de Proteção de Dados Pessoais
}

\author{
Flávia Renata Beppu ${ }^{1,3}$, Cristiano Maciel $^{1,2}$ \\ 'Programa de Pós-graduação em Educação - Universidade Federal de Mato Grosso \\ (UFMT) - Cuiabá - MT - Brasil \\ ${ }^{2}$ Instituto de Computação - Universidade Federal de Mato Grosso (UFMT) - \\ Cuiabá - MT - Brasil \\ ${ }^{3}$ Ministério Público do Estado de Mato Grosso (MPMT) - Cuiabá - MT - Brasil \\ flaviarbeppu@gmail.com, crismacegmail.com
}

\begin{abstract}
This article analyzes the implications of the Brazilian personal data protection law for cases of post-mortem digital legacy treatment. Therefore, it investigates aspects of this law that can contribute to the development of software and internet applications that treat users' digital assets. The research was carried out based on a literature review, analysis of the relevant legislation and some legislative proposals to regulate the matter. The results show for the possibility of applying the principles and foundations of the data protection law as an axiological matrix for the treatment of the digital legacy, in line with the national constitutional order.
\end{abstract}

Resumo. Este artigo analisa as implicações da lei geral de proteção de dados pessoais brasileira aos casos de tratamento de legado digital pós-morte. Para tanto, investiga aspectos dessa lei que podem contribuir para o desenvolvimento de softwares e aplicações de internet que tratam ativos digitais de usuários. A pesquisa foi realizada a partir de revisão da literatura, de análise da legislação pertinente e de propostas legislativas de regulamentação da matéria. Os resultados demonstram a possibilidade de aplicação dos princípios e fundamentos da lei de proteção de dados como matriz axiológica para o tratamento do legado digital, em consonância com o ordenamento constitucional pátrio.

\section{Introdução}

A tecnologia tem tomado um espaço cada vez maior em nossa vida. Desde o lançamento do PC (personal computer), em 1981, pela IBM, (BLUM, 2015, p. 180), até os dias atuais, sobretudo após o fenômeno da internet, saímos do patamar de subutilização do computador para um cenário de dependência significativa dessa ferramenta para realização de toda sorte de atividades. Somos "controlados por diversos aplicativos que organizam nossas agendas, comunicação, calendários, videoconferências, atividade física, transporte, alimentação, localização, lazer etc. 
Para se ter uma ideia, em 2017, o relatório das Nações Unidas sobre Comércio e Desenvolvimento (UNCTAD) ${ }^{1}$ apontou o Brasil como o quarto país com mais usuários de internet, com 120 milhões, representando $59 \%$ da sua população ${ }^{2}$. No ano seguinte, o Comitê Gestor da Internet no Brasil (CGI), por meio do Centro Regional de Estudos para o Desenvolvimento da Sociedade da Informação do Núcleo de Informação e Coordenação do Ponto BR (CETIC/NICBR), divulgou pesquisa revelando o uso da internet por $70 \%$ da população, equivalente a 126,9 milhões de brasileiros. ${ }^{3}$

A vida virtual, por assim dizer, ganha cada vez mais espaço e importância em nosso dia-a-dia e com a inserção cada vez maior de dados pessoais na rede, surge a demanda de tratamento desses dados, a fim de preservar as garantias fundamentais dos usuários. Via de consequência, surge a necessidade de tratamento da morte dos usuários nas aplicações. Esse ponto tem gerado dúvidas e discussões no campo do tratamento do legado digital, que carece de regulamentação específica que confira maior estabilidade e segurança jurídica para desenvolvedores de sistemas e provedores de aplicações que tratam dados de mortos. Nessa esteira, a nova lei de proteção de dados brasileira (LGPD) pode contribuir para a construção de um caminho normativo para essa regulação.

Há que se considerar a modelagem da privacidade em diferentes contextos, conforme advertem Maciel e Pereira (2012), devido ao seu caráter multicontextual, o que dificulta o estabelecimento de uma abordagem restrita e absoluta a esse respeito. As tecnologias, e a profusão de seu uso, têm trazido à tona muitas questões técnicas que se antecipam às legais. Assim, esta pesquisa traz como problema a falta de regulamentação jurídica para o tratamento do legado digital pós morte e as consequências que essa insegurança pode gerar, seja na perspectiva da privacidade do titular ou sob a ótica do desenvolvimento de novas aplicações e funcionalidades. Nesse contexto, o trabalho tem como objetivo analisar as implicações da LGPD aos casos de tratamento de dados de pessoas mortas no contexto do ambiente digital.

O presente estudo desenvolver-se-á por pesquisa exploratória (PIOVESAN; TEMPORINI,1995), a partir de revisão bibliográfica e análise documental, com recorte na legislação pertinente e em projetos legislativos que buscaram regulamentar o assunto, a fim de ampliar a investigação do tema e compreender melhor as suas nuances.

Este artigo está estruturado como segue. Após essa introdução, há a seção sobre Legado Digital, que explora conceitos desta área, incluindo propostas de regulamentação. Já na seção 3, pontos específicos da LGPD são analisados e cotejados com o tema, permitindo algumas reflexões e considerações, trazidas nas seções 4 e 5 , respectivamente.

\section{Legado digital}

Os desafios relacionados à temática de privacidade no mundo conectado, interação póstuma e legado digital pós morte são debatidos na área de Computação no Brasil há quase uma década, quando passou a integrar o espaço de pesquisas da Sociedade Brasileira de Computação (SBC), como relatam Maciel e Pereira (2012). No entanto,

\footnotetext{
${ }^{1}$ Information Economy Report, 2017. Disponível em:

https://unctad.org/en/PublicationsLibrary/ier2017 en.pdf

${ }^{2}$ Disponível em https://exame.abril.com.br/tecnologia/brasil-e-o-4o-pais-em-numero-de-usuarios-deinternet/; acesso em 18.04.2020.

${ }^{3}$ https://cgi.br/noticia/releases/tic-domicilios-2018-revela-que-40-8-milhoes-de-usuarios-de-internetutilizam-aplicativos-de-taxi-ou-transporte/; acesso em 18.04.2020.
} 
ainda não há consenso sobre a regulação, social e jurídica, acerca do assunto, o que demonstra a pertinência e a necessidade de pesquisas nessa seara, conforme se demonstrará adiante.

Por legado digital entende-se, segundo Carrol e Romano, "a somatória das posses digitais que você deixou para os outros" (MACIEL, 2011). Para Edwards e Harbinja (2013, p. 116), ativos digitais transferíveis seriam, de forma ampla e não exaustiva, bens intangíveis de informação, associados ao mundo online ou digital, a exemplo de perfis de redes sociais (Facebook, Twiter etc.), e-mails, bases de dados, imagem, som, vídeo, senhas de acesso a bens e serviços digitais e vários outros.

Embora o conceito soe como simples, os desafios que o cercam são complexos. A uma, por envolverem questões interdisciplinares e interesses aparentemente paradoxais como privacidade e a liberdade de comunicação e expressão. A duas, em virtude da divergência sobre se deve prevalecer a ideia de finitude da vida no mundo digital (delecionistas) ou a preservação do legado para os descendentes (preservacionistas). Ou ainda, como se dará o gerenciamento dos dados do falecido, havendo ou não testamento digital (MACIEL; PEREIRA, 2012).

\subsection{Algumas propostas de regulamentação}

No que concerne ao gerenciamento dos dados, mais precisamente à transmissão do legado digital, ao longo da última década têm sido apresentados projetos de lei na Câmara e no Senado, pretendendo regulamentar a matéria. Para esse estudo selecionamos dois projetos que tramitaram em 2012 e cujos textos foram reapresentados em outras legislaturas.

O PL 4847/2012 4 tratava da herança digital, definida no projeto como sendo "tudo o que é possível guardar ou acumular em espaço virtual" e propunha a inserção do Capítulo II-A (do Livro IV - Título I) e dos artigos 1.797-A a 1.797-C no Código Civil brasileiro. A proposta estabelecia que se o usuário não tivesse deixado testamento acerca da herança digital, esta seria destinada aos herdeiros legítimos. Ao herdeiro caberia, conforme o texto, definir o destino das contas do falecido, podendo, (a) transformá-las em memorial, deixando o acesso restrito a amigos confirmados e mantendo apenas o conteúdo principal ou; (b) apagar todos os dados do usuário ou; (c) remover a conta do antigo usuário.

O autor declara na justificativa que "tudo o que é possível guardar em um espaço virtual - como músicas e fotos, passa a fazer parte do patrimônio das pessoas e, consequentemente, da chamada "herança digital"." Em nenhum momento do projeto ou da justificativa foi tratada a faceta dos direitos da personalidade ${ }^{5}$, que compreende também a temática do legado digital.

Na mesma linha caminhou o PL 4099/20126, que de maneira mais resumida, apenas alterando o artigo 1.788 do Código Civil, previa que seriam transmitidos aos

\footnotetext{
${ }^{4}$ Disponível em:

https://www.camara.leg.br/proposicoesWeb/prop_mostrarintegra?codteor=1049733\&filename=PL+48 47/2012, acesso em 27.04.2020.

${ }^{5}$ Aqueles relacionados aos atributos inatos do ser humano (ex: honra, imagem, privacidade). Os direitos da personalidade são tratados pelo Código Civil nos artigos 11 a 21.

${ }^{6}$ Disponível em:

https://www.camara.leg.br/proposicoesWeb/prop_mostrarintegra?codteor $=1004679 \&$ filename $=P L+40$ 99/2012, acesso em 27.04.2020.
} 
herdeiros "todos os conteúdos de contas ou arquivos digitais de titularidade do autor da herança." Ao justificar a proposição, o autor alega:

"Têm sido levadas aos Tribunais situações em que as famílias de pessoas falecidas desejam obter acesso a arquivos ou contas armazenadas em serviços de internet e as soluções tem sido muito díspares, gerando tratamento diferenciado e muitas vezes injustos em situações assemelhadas."

$[\ldots]$

"O melhor é fazer com que o direito sucessório atinja essas situações, regularizando e uniformizando o tratamento, deixando claro que os herdeiros receberão na herança o acesso e total controle dessas contas e arquivos digitais."

Esse projeto, arquivado na Câmara, foi reapresentado no Senado, pelo mesmo parlamentar, e encontra-se em tramitação, sob número 6468/2019 ${ }^{7}$.

De modo mais pontual, porém no mesmo diapasão, foi o PL no $1331 / 2015$, que pretendia alterar o Marco Civil da Internet. O projeto tratava sobre a possibilidade de exclusão definitiva dos dados pessoais de usuário de internet morto ou ausente, "a requerimento do cônjuge, dos ascendentes ou dos descendentes, até o terceiro grau, ao término da relação entre as partes, ressalvadas as hipóteses de guarda obrigatória de registros previstas nesta Lei" (inciso X do artigo $7^{\circ}$ ). Contudo, esse projeto também foi arquivado pela Câmara, no final de 2019, em razão do término da legislatura.

Ressai evidente que as propostas legislativas têm tratado o assunto do legado digital pós morte com conotação de propriedade bem como a transmissão sob a ótica dos herdeiros, desconsiderando por completo os interesses afetos à seara da personalidade do titular, como a privacidade (MACIEL et al., 2015). Tal caminho mostra-se incompleto, uma vez que ignora a natureza de grande quantidade de dados e informações armazenadas pelos usuários em aplicações de internet, confiando que aquele conteúdo ali depositado estaria preservado, ou que seria compartilhado apenas com membros daquela comunidade ou rede de contatos.

O conteúdo de um e-mail, ou conversas, depoimentos e até fotos, que compõem o legado digital do usuário falecido, devem merecer especial atenção, por estarem no campo da intimidade do titular. Não podem ser simplesmente transmitidos na cadeia sucessória como se transfere uma casa ou um veículo, ou direitos autorais e demais bens intangíveis monetizados ou monetizáveis. Em linha com o que sustenta Leal (2018), não há sucessão de direitos da personalidade (por serem personalíssimos, intransmissíveis) no Direito brasileiro, mas $\operatorname{sim}$ " [...] ta tutela de um centro de interesses relacionado à personalidade[...]", por compreender o aspecto existencial do falecido.

\section{Aspectos jurídico-normativos da privacidade e proteção de dados}

No contexto da vida digital e do universo virtual, a privacidade e a proteção dos dados pessoais ganham atenção e notoriedade mundo afora, sobretudo após a entrada em vigor do regulamento europeu, a General Data Protection Regulation $\left(\mathrm{GDPR}^{8}\right)$. Em que pese não ser o único regulamento a tratar do assunto, está aqui mencionado em razão da forte

\footnotetext{
${ }^{7}$ https://www25.senado.leg.br/web/atividade/materias/-/materia/140239, acesso em 27.04.2020.

${ }^{8}$ Disponível em: https://eur-lex.europa.eu/legalcontent/PT/TXT/PDF/?uri=CELEX:32016R0679\&from=PT
} 
influência desse estatuto na lei brasileira de proteção de dados.

O novo regulamento europeu, que sucedeu a Diretiva 95/46, trouxe, em termos de enforcement, um ganho em relação àquela, por se tratar de uma norma autoaplicável, exigível pelos cidadãos de todos os Estados-membros da União Europeia desde 25.05.2018 (MALDONADO e BLUM, 2019, p. 21).

No Brasil, o direito à privacidade possui assento constitucional. A Constituição Federal de 1988 cunhou a inviolabilidade da intimidade e da vida privada no rol de direitos e garantias fundamentais ${ }^{9}$. Não há, portanto, como alude Pinheiro (2016, p. 95), lacuna jurídica em sede de solução de privacidade na internet. Contudo, como ressalta Sombra $(2019$, p. 132), o país foi a última democracia da América Latina a estabelecer um marco regulatório de proteção de dados pessoais.

Em 2014, diante da necessidade premente de regulação do uso da internet, sobreveio o seu Marco Civil (Lei $\left.{ }^{0} 12.965\right)^{10}$, que trouxe entre os seus princípios o direito à privacidade e à proteção de dados, porém este dependendo de lei, que só veio em 2018. A Lei $n^{\circ}$ 13.709/2018 (Lei Geral de Proteção de Dados Pessoais), apelidada de LGPD, foi publicada em 15.08.2018 ${ }^{11}$, estabelecendo normas para o tratamento de dados pessoais tanto em meios digitais quanto físicos.

Nesse contexto, a discussão sobre privacidade e proteção de dados pessoais deve passar pelos parâmetros normativos daquilo que se quer proteger e pelo contexto em que é considerada. Esses parâmetros devem guiar o desenvolvimento de softwares e aplicações de internet.

Importa observar que a LGPD, na mesma linha da GDPR, refere-se ao tratamento de dados de pessoas físicas, não alcançando os dados de pessoas jurídicas. Vale mencionar, também, o caráter nacional da norma brasileira, isto é, ela deve ser observada no âmbito da União, dos Estados, do Distrito Federal e dos Municípios ${ }^{12}$.

Por "tratamento", a lei considera "toda operação realizada com dados pessoais, como as que se referem a coleta, produção, recepção, classificação, utilização, acesso, reprodução, transmissão, distribuição, processamento, arquivamento, armazenamento, eliminação, avaliação ou controle da informação, modificação, comunicação, transferência, difusão ou extração", conforme artigo $5^{\circ}$, inciso X.

A título de ilustração, o preenchimento de dados pessoais para criação de uma conta, por exemplo, do Facebook, é uma forma de tratamento na modalidade "coleta", onde a empresa provedora da aplicação (Facebook) passa a ser "controladora" dos dados pessoais coletados do "titular" (o usuário).

Oportuno salientar, sobre a norma de aplicabilidade, que a lei brasileira, assim como a GDPR, fixa a regra da extraterritorialidade. Assim, em síntese, se a operação de

\footnotetext{
${ }^{9}$ Art. 5o, X, CF.

${ }^{10}$ Lei $n$ o 12.965, de 23.04.2014, estabeleceu princípios, garantias, direitos e deveres para o uso da internet no país e foi regulamentada pelo Decreto $\mathrm{n}$ ㅇ 8.171, de 11.05.2016.

${ }^{11}$ A LGPD ainda não está inteiramente vigente, o que ocorreria em agosto de 2020 (cf. art. 65, II); todavia, a Medida Provisória no 959, editada em 29.04.2020 (pendente de conversão em lei pelo Congresso), prorrogou a vigência da lei para 03.05.2021. Nesse ínterim, sobreveio a Lei no 14.010, que estabeleceu a entrada em vigor dos artigos 52, 53 e 54 em 01.08.2021.

12 Art. 1으, caput e parágrafo único, LGPD.
} 
tratamento for realizada no Brasil, a lei brasileira será aplicada, não importando o local da sede da empresa ou o país onde esteja localizado o dado ${ }^{13}$.

No que concerne ao tratamento de dados de mortos, a norma europeia diz expressamente que "não se aplica aos dados pessoais de pessoas falecidas", prevendo que os "Estados-Membros poderão estabelecer regras para o tratamento dos dados pessoais de pessoas falecidas. ${ }^{14}$. A LGPD, por sua vez, nada menciona a esse respeito.

Entretanto, os princípios e fundamentos da lei geral podem orientar o desenho do tratamento de dados pessoais de mortos, como uma extensão do âmbito de proteção que já era observado enquanto usuário vivo. Tal desenho, por sua vez, orientaria o desenvolvimento de sistemas.

A análise do estatuto normativo brasileiro e da bibliografia correlata, ao longo dessa pesquisa, culminam por elucidar essa tendência.

\subsection{A LGPD e os mortos}

A LGPD, conforme mencionado alhures, volta-se à proteção dos dados pessoais das pessoas naturais (Art. $1^{\circ}$, caput). O Código Civil brasileiro, no seu artigo $6^{\circ}$, primeira parte, estabelece que a existência da pessoa natural termina com a morte. Todavia, impõese a constatação de que, atualmente, existe para muitos uma vida no mundo virtual tão ou mais ativa que no mundo concreto, digamos assim, que não deixa de existir, de maneira síncrona, com o falecimento do corpo físico, ao menos em alguns aspectos.

Assim sendo, como a temática ainda não está bem definida, nem no campo técnico tampouco na seara normativa, vislumbra-se a possibilidade de a Lei Geral de Proteção de Dados Pessoais - LGPD oferecer uma nova perspectiva acerca do tratamento do legado digital pós morte, orientando o desenvolvimento de softwares e aplicações de internet.

Entre os fundamentos da proteção de dados pessoais elencados no $\operatorname{artigo} 2^{\circ}$ da lei, estão o respeito à privacidade, a inviolabilidade da intimidade, da honra e da imagem e os direitos humanos, o livre desenvolvimento da personalidade, a dignidade e o exercício da cidadania pelas pessoas naturais.

A privacidade versada na LGPD caminha mais no sentido de conferir ao titular o poder decisório acerca de quais dados seus poderão ser utilizados ou compartilhados, com quem e com qual finalidade, do que no sentido de vedar qualquer forma de compartilhamento. Nota-se que a privacidade, aqui, vai de mãos dadas com outro fundamento da lei, o da autodeterminação informativa ${ }^{15}$, que se traduz, conforme Maldonado e Blum (2019, p 27) no "controle pessoal sobre o trânsito de dados relativos ao próprio titular", devendo se dar, como ressalta SOMBRA (2019, p. 149), com consciência e de forma transparente, sem apelos psicológicos e econômicos.

Desse modo, na linha da percepção contextual mencionada por Sombra (2019, p. 143), a privacidade deve ser compreendida segundo o complexo e multifacetado universo que a circunda, com novas demandas por liberdade, autonomia e inovação. $\mathrm{O}$ autor parte da diversidade cultural e dos múltiplos contextos de interação social para propor um modelo normativo com parâmetros seguros e flexíveis do sistema de proteção da

\footnotetext{
${ }^{13}$ Art. 3으, LGPD.

14 Item 27 das considerações iniciais.

${ }^{15}$ Art. 2으, II, LGPD.
} 
privacidade e, por conseguinte, da proteção de dados. Advoga a adoção de diretrizes principiológicas, a contemplar não somente os impactos individuais da privacidade, mas também a expectativa social de proteção.

Tal sustentação converge para a preocupação evidenciada na LGPD, ao estabelecer seus fundamentos e princípios, a fim de direcionar as decisões e modelos de conformação (compliance), ciente de que as situações específicas previstas no texto normativo não são capazes de regular e prever toda a casuística de tratamento, relações e arranjos contratuais, mormente diante da velocidade tecnológica e da dinâmica social, características da fluidez do mundo contemporâneo.

Assim, o regulamento nacional fixa como ponto de partida da proteção de dados o titular, devolvendo a ele o poder decisório quanto aos seus dados e a forma de tratamento. Na linha do que argumenta Sombra (2019, p. 173), a matriz axiológica dos direitos dos titulares estabelecidos na LGPD será a autodeterminação, sobretudo ante a "magnitude da capacidade de processamento proporcionada pelo big data e data analytics".

Outro princípio importante contemplado na lei é o da finalidade, ou seja, tratar o dado com o propósito legítimo, específico, explícito e informado ao titular. Dito de outra forma, deve haver observância ao propósito do tratamento e transparência para com o titular. Tal princípio figura em harmonia com o da necessidade, que pressupõe a coleta proporcional de dados e o tratamento mínimo necessário à realização da finalidade informada ${ }^{16}$.

Além disso, impõe-se considerar a metodologia da privacidade, de modo a abarcar a regra da privacidade desde a concepção do projeto (privacy by design ${ }^{17}$, e por padrão ( privacy by default), sendo esta decorrente daquela. A metodologia de privacy by design, na explicação de Maldonado (2019, pp. 221/225), foi desenvolvida por Ann Cavoukian e compreende sete princípios, quais sejam, (i) proativo não reativo; preventivo não corretivo; (ii) privacidade como configuração padrão (privacy by default); (iii) privacidade embarcada no design; (iv) funcionalidade integral; (v) segurança de ponta a ponta (em todo o ciclo de vida do dado); (vi) visibilidade e transparência; e (vii) respeito à privacidade do usuário.

Oportunamente, importa considerar, em especial, duas hipóteses de tratamento de dados pessoais do titular autorizadas pela LGPD. A primeira é o consentimento, definido na LGPD como manifestação livre, informada e inequívoca, pela qual o titular concorda com o tratamento de seus dados pessoais para uma finalidade determinada ${ }^{18}$. Nos contornos trazidos pelo artigo $8^{\circ}$ da lei, o consentimento deve ser expresso e vir em cláusula destacada. Deve, ainda, referir-se a finalidade determinada, sendo nulas as autorizações de tratamento genéricas.

A segunda refere-se ao legítimo interesse do controlador. Essa hipótese pode justificar o tratamento realizado, exceto se prevalecerem direitos e liberdades fundamentais do titular ${ }^{19}$ e desde que seja para finalidades legítimas, consideradas a partir de situações concretas, como por exemplo, a proteção do exercício regular de direitos do

\footnotetext{
${ }^{16}$ Art. 60, l e III, LGPD.

${ }^{17}$ Art. 46, § 20, LGPD.

${ }^{18}$ Art. 50, XII, LGPD.

${ }^{19}$ Art. 70, IX, LGPD.
} 
titular ou prestação de serviços que o beneficiem, respeitadas as legítimas expectativas dele e os direitos e liberdades fundamentais ${ }^{20}$. No caso de legítimo interesse do controlador, o tratamento deve limitar-se àqueles dados estritamente necessários à finalidade pretendida ${ }^{21}$.

Portanto, nota-se que nas duas hipóteses de tratamento, a lei prevê expressamente a condição de respeito ao princípio da finalidade.

\section{Reflexões}

Analisada a matriz principiológica da LGPD, convém refletir sobre as possibilidades de tratamento de dados pessoais supracitadas e como elas podem orientar o desenvolvimento de softwares e aplicações que tratam dados de pessoas mortas e do seu legado digital.

$\mathrm{Na}$ esteira do que o regulamento considera tratamento de dados pessoais, conforme citado na seção anterior, é razoável e até esperado que contas de usuários falecidos em redes sociais, e-mails e outras aplicações recebam algum tipo de tratamento por parte dos respectivos controladores e/ou operadores, ainda que seja para arquivar ou eliminar a conta, uma vez que o titular não poderá fazê-lo por si só.

Assim, observados os parâmetros legais já adotados para o tratamento dos dados do usuário em vida, o legítimo interesse pode vir a fundamentar o seu tratamento, a fim de dar a destinação legal ou contratual, conforme previamente orientado pelo usuário, ao legado digital deixado pelo morto.

No aspecto operacional, dispor o artefato tecnológico de opções de consentimento para o tratamento dos dados para a destinação post mortem apresenta uma maior segurança (do ponto de vista do controlador) e maior proteção (na ótica do titular) em relação ao tratamento. A LGPD avança, no aspecto normativo, em relação à consideração da vontade do titular (aspecto volitivo), o que reforça a possibilidade de solução contratual do tratamento do legado digital, ou seja, o desenvolvimento dos modelos de testamentos digitais a serem disponibilizados nas aplicações.

Nesse sentido, havendo a necessidade de tratar os ativos digitais após a morte do usuário, as opções de funcionalidades, em consonância com o ordenamento jurídico vigente, devem ser previstas nos termos de uso e políticas de privacidade dos sistemas e aplicações de internet, de modo a orientar o tratamento dos dados do usuário após sua morte, conforme se extrai de Viana et al. (2020, pp. 73/76).

No caso da conversão em memorial, por exemplo, questões secundárias surgem no que tange às opções de desenho desse tipo de perfil, quais dados poderiam ser expostos, limitação ou não de acesso e prazo de duração do memorial. Isso porque o controlador não pode descurar da proteção dos dados de terceiros que se relacionavam com o titular. Ademais, o perfil do usuário também importa para a definição do memorial. Não é razoável, pois, que se dê o mesmo tratamento, em termos de privacidade, no caso da morte de um usuário "youtuber" e de outro usuário "comum", cujo memorial se prestará apenas ao luto e memórias dos seus contatos e entes queridos (EDWARDS e HARBINJA, 2013, pp. 116/117).

\footnotetext{
${ }^{20}$ Art. 10, II, LGPD.

${ }^{21}$ Art. 10, § 1으, LGPD.
} 
Analisando a questão da limitação de acesso ao perfil sob a luz do consentimento, tal como definido pela LGPD, dessome-se que tal limitação deveria levar em conta se o perfil do usuário já era público (aberto), hipótese em que bastaria a preservação dos conteúdos compartilhados em modo privado pelos contatos, uma vez que os dados do chamado "feed" já eram públicos. Por outro lado, caso o usuário tenha muitas restrições de privacidade no seu perfil, talvez nem seja viável habilitar a opção de conversão em memorial. Porém, caso haja a conversão, a limitação das opções de privacidade concedidas ao "herdeiro" deveria respeitar as características do perfil do usuário falecido, em atenção aos aspectos volitivos manifestados em vida, conforme se depreende da ponderação feita por Maciel (2011).

A propósito do tema, vale citar o precedente julgado pela justiça alemã, em que os pais de uma menina de 15 anos, que morreu em uma estação subterrânea do metrô em 2012, acionaram o Facebook, pleiteando acesso à conta da filha, no intuito de tentar esclarecer se a morte foi decorrente de suicídio. O Tribunal alemão, reformando a decisão de primeira instância, negou o pedido, entendendo que o acesso à conta da filha representaria uma violação à expectativa de privacidade dos seus contatos (LEAL, 2018).

Nesse ponto, inclusive, há que se levar em conta que os terceiros, na situação mencionada, são usuários/titulares vivos, o que atrai, sem qualquer dúvida ou questionamento, a aplicação da LGPD, devendo seus dados ser tratados pelo controlador e pelo operador de acordo com os preceitos do regulamento, sob pena de serem acionados por aqueles terceiros atingidos pela exposição dos dados.

No mais, a LGPD amplia o direito de exclusão dos dados previstos no Marco Civil da Internet21, para conferir ao titular de dados pessoais o direito à eliminação. $\mathrm{O}$ seu artigo $5^{\circ}$, XIV, define eliminação como sendo a "exclusão de dado ou de conjunto de dados armazenados em banco de dados, independentemente do procedimento empregado". Maldonado e Blum (2019, pp. 122/124) explicam que é a exclusão definitiva do poder de controle do controlador dos dados, não importando o procedimento ou a localização desses dados. Ainda, caso esses dados tenham sido compartilhados com terceiros, deverá informar imediatamente os demais agentes para que procedam da mesma forma.

O artigo 16 prevê que os dados serão eliminados ao fim do tratamento, dentro dos limites técnicos, ressalvados os casos de cumprimento de obrigação legal, ou se for para estudo por órgão de pesquisa, garantida, sempre que possível, a anonimização, transferência legítima a terceiros e uso exclusivo do controlador, desde que anonimizados. Já o artigo 18 assegura o direito à eliminação em caso de dados desnecessários, excessivos ou tratados em desconformidade com a LGPD; ou se o titular retirar o consentimento e não houver alguma das ressalvas mencionadas acima.

$\mathrm{O}$ direito à eliminação assemelha-se ao direito ao apagamento (esquecimento) fixado na GDPR22. A esse respeito, conforme Pinheiro (2016, pp. 490/491), o direito ao esquecimento é o direito conferido ao ser humano de ter um fato vexatório da sua vida esquecido após determinado tempo. Ressalta que esse direito foi tratado, no ordenamento brasileiro, pelo Enunciado 531 da VI Jornada de Direito Civil do Conselho da Justiça Federal, que o insere no âmbito da tutela da dignidade da pessoa humana na sociedade da informação. Na Europa, antes mesmo da GDPR, a Diretiva 95/46/CE e outras agências de proteção de dados dos países membros já aplicavam o direito ao esquecimento (MACIEL et al., 2015). 


\section{Considerações Finais}

$\mathrm{Na}$ medida em que o foco regulatório da LGPD é o tratamento de dados pessoais de pessoa natural, cuja existência, de acordo com o Código Civil brasileiro, finda-se com a morte do indivíduo, infere-se que o regulamento (regras/obrigações e sanções) não alcança diretamente o tratamento de dados de pessoas mortas (SOMBRA, 2019, p. 156), ao menos da forma como a morte é concebida e tratada pelo ordenamento jurídico ora vigente. Não obstante, a própria concepção de morte vem sendo indagada, ante os avanços tecnológicos em torno da imortalidade, como aquela por meio de software, conforme abordado por Galvão et al. (2017), que considera "técnicas de IA [inteligência artificial], redes neurais, big data, aprendizado de máquina e a interdisciplinaridade com outras áreas (como psicologia e filosofia) para a replicação de um ser humano".

Por outro lado, tendo-se a proteção dos dados pessoais como um desdobramento do direito constitucional à intimidade e à vida privada (PINHEIRO, 2016, p. 95), podese concluir que a LGPD, sobretudo no que se refere a fundamentos e princípios, é uma diretriz segura a orientar as ações de tratamento do legado digital post mortem, na perspectiva da "tutela do centro de interesses" relacionado à personalidade do indivíduo falecido, compreendendo o seu aspecto existencial (LEAL, 2018).

Os aspectos da LGPD analisados nas seções 3 e 4 evidenciam a preocupação do regulamento com a privacidade e a intimidade do titular. Leva em conta, ainda, a sua autodeterminação e a sua volição, em especial no relevo que confere ao instituto do consentimento. Esse ponto, aliás, reforça a importância de se tratar esses aspectos nos termos de uso e políticas de privacidade de softwares e aplicações de internet, pré configurados pelo usuário titular da conta.

Já se verificou que a geração internet deseja manifestar sua volição quanto ao destino do legado digital (MACIEL; PEREIRA, 2012). Todavia, na linha principiológica estabelecida pela LGPD, essas "cláusulas" de consentimento e de configuração de aspectos do legado devem vir de forma clara e destacada nos termos de uso e políticas de privacidade, em atenção ao princípio da transparência e da autodeterminação do usuário. Isso, inclusive, deve ser um requisito do sistema, como afirmam Coleti et al. (2018), visando a proporcionar privacidade, segurança e controle do titular sobre os dados produzidos.

Por fim, há que se ter em mente, sempre, que nos casos de tratamento de dados pessoais de titulares vivos em contas ou memoriais dos usuários mortos (seus amigos/contatos), a LGPD será aplicada integralmente. O mesmo se dá em caso de compartilhamento desses dados com terceiros, no caso do herdeiro digital, com poderes para tratar dados desses amigos/contatos do falecido, sem consentimento desses titulares. Nessa situação, havendo a permissão (legal ou contratual) de edição dos dados ou de exposição em memorial pelo herdeiro digital, tal tratamento deve ocorrer nos limites do consentimento dos titulares (terceiros) vivos. No caso de ampliação desses limites, novo consentimento deveria ser colhido. No que se refere ao tema compartilhamento com terceiros, levantamentos perpetrados por Coleti et al. (2018) apontam que as aplicações destacam suas relações com terceiros, embora não detalhem quem são e quais os objetivos do compartilhamento. Por essa razão a lei não pode ser simplesmente ignorada quando do desenho desses artefatos digitais.

Assim sendo, a tendência que se vislumbra para o tratamento do legado digital post mortem caminha na mesma lógica de corregulação delineada por Sombra (2019), 
onde atuam no mesmo sistema, de um lado o ordenamento jurídico (regulação estatal) e de outro provedores de aplicações e desenvolvedores de softwares, de modo a garantir a autodeterminação informativa do usuário, bem como transparência e accountability. Seja por impulso da lei ou do risco de sanções, o código (de softwares), em linha do que sustenta Lawrence Lessig, protagonizará, em muitas situações, a determinação de comportamentos, pois é mais fácil violar uma lei do que violar um código-fonte (PINHEIRO, 2016, p. 56).

No Brasil, essa corregulação ganha, com o advento da LGPD, outro ente relevante que é o próprio usuário, no exercício da autodeterminação informativa, isto é, decidir quais dados seus poderão ser tratados e para qual finalidade, com quem e para que serão compartilhados.

A limitação na falta de regulamentação legal específica ainda é um obstáculo ao tratamento do legado digital no país, porém a lei nacional de proteção de dados estabelece diretrizes importantes para esse tratamento, por meio de softwares e aplicações. Sendo a LGPD a lei específica sobre proteção de dados pessoais no Brasil, ela centralizará o sistema normativo em relação a essa matéria, passando a orientar decisões judiciais e até futuras regulamentações sobre o legado digital pós morte e o seu tratamento.

Ressai das reflexões apresentadas outras questões, que ainda carecem de respostas, do ponto de vista legal, como a definição da forma de tratamento do legado, os bens ou ativos digitais passíveis de sucessão, os casos de aplicação do regime de sucessão legítima e testamentária do legado digital, os modelos de perfis ou memoriais dos usuários de aplicações falecidos, as finalidades e funcionalidades de tratamento consideradas lícitas, o prazo de duração do tratamento e a forma de eliminação após esse período.

Dessa forma, o campo de pesquisa nessa área ainda é extenso e trabalhos futuros podem ser desenvolvidos se utilizando de variadas metodologias. Ainda, é importante analisar o que as diferentes gerações conhecem da LGPD, o que pensam sobre privacidade e sua repercussão no caso do legado digital, deixado após a morte do usuário.

\section{Agradecimentos}

Esta pesquisa contou com o apoio do Conselho Nacional de Desenvolvimento Científico e Tecnológico - CNPq, bem como do Ministério Público do Estado de Mato Grosso MPMT.

\section{Referências}

BLUM, Renato Opice (2015) "O Marco Civil da Internet e a Educação Digital no Brasil.” In: Educação Digital, Editado por Juliana Abrussio, Revista dos Tribunais, São Paulo.

COLETI, Thiago Adriano, MORANDINI, Marcelo, FILGUEIRAS, Lucia Vilela Leite e CORRÊA, Pedro Luiz Pizzigatti (2018) "Análise da Transparência de Dados Pessoais em Políticas de Privacidade de Dados.” In: WORKSHOP SOBRE ASPECTOS DA INTERAÇÃO HUMANO-COMPUTADOR NA WEB SOCIAL (WAIHCWS), Anais do IX Workshop sobre Aspectos da Interação Humano-Computador para a Web Social, Belém, Editado por Sociedade Brasileira de Computação, Porto Alegre.

EDWARDS, Lilian e HARBINJA, Edina (2013) “"What happens to my Facebook profile when I die?": Legal issues around transmission of digital assets on death." In: Digital 
Legacy and Interaction: post mortem issues, Editado por Cristiano Maciel e Vinícius Carvalho Pereira, Springer International Publishing Switzerland.

LEAL, Livia Teixeira (2018) "Internet e morte do usuário: a necessária superação do paradigma da herança digital.”, Revista Brasileira de Direito Civil - RBDCilvil, Belo Horizonte.

MACIEL, Cristiano (2011) "Issues of the Social Web interaction project faced with afterlife digital legacy." In: Proceedings of IHC+CLIHC 2011. (Porto de Galinhas, PE, out 2011), http://dl.acm.org/citation.cfm?id=2254441

MACIEL, Cristiano, GARCIA, Ana Cristina Bicharra e VITERBO, José (2017) "Life Beyond the Physical Body: The Possibilities of Digital Immortality.” In: 2017 XLIII Latin American Computer Conference (CLEI), http://ieeexplore.ieee.org/document/8226419/

MACIEL, Cristiano e PEREIRA, Vinícius Carvalho (2014) "A Morte como Parte da Vida Digital: uma Agenda de Pesquisa em IHC.”, IHC 2014 Proceedings - Position Paper, Foz do Iguaçu, Paraná, Brasil.

MACIEL, Cristiano e PEREIRA, Vinícius Carvalho (2012) "The internet generation and its representations of death: considerations for posthumous interaction projects." In: Proceedings of the 11th Brazilian Symposium on Human Factors in Computing Systems (IHC '12), Editado por Brazilian Computer Society, Porto Alegre, Brazil, http://dl.acm.org/citation.cfm?id=2393548\&CFID=169216683\&CFTOKEN=455292 44

MALDONADO, Viviane da Nóbrega (2019) "LGPD: Lei Geral de Proteção de Dados: manual de implementação.” Thomson Reuters Brasil, São Paulo.

MALDONADO, Viviane da Nóbrega e BLUM, Renato Opice [Coord.] (2019) "LGPD Lei Geral de Proteção de Dados Comentada.”, 2a Edição, Editora Thompson e Reuters Brasil, São Paulo.

PINHEIRO, Patrícia Peck (2016) “Direito Digital”, 6 a Edição, Editora Saraiva, São Paulo.

PIOVESAN, Armando e TEMPORINI, Edméa Rita (1995) "Pesquisa exploratória: procedimento metodológico para o estudo de fatores humanos no campo da saúde pública.”, $\quad$ http://www.scielo.br/scielo.php?script=sci_arttext\&pid=S003489101995000400010\&lng=pt\&nrm=iso

SOMBRA, Thiago Luís Santos (2019) "Fundamentos da regulação da privacidade e proteção de dados pessoais: pluralismo jurídico e transparência em perspectiva.", Thompson Reuters Brasil, São Paulo.

VIANA, Gabriel Trocha, MACIEL, Cristiano, SOUZA, Patrícia Cristiane e ARRUDA, Ney Alves (2020) "Analysis of terms of use and privacy policies in social networks to treat user's death.", In: Software ecosystems, sustainability and human values in the social web. Edited by Rodrigo Pereira dos Santos e Cristiano Maciel e José Viterbo, Springer Nature Switzerland. 